\title{
FEBRE MACULOSA NO MUNICÍPIO DE PEDREIRA, SP, BRASIL. INQUÉRITO SOROLÓGICO
}

\author{
Vania Martins Fontes Del Guercio, Marilú Mendes M. Rocha, Heloísa H.B. \\ Melles, Virgília C.L. de Lima e Marta G. Pignatti
}

\begin{abstract}
Casos de febre maculosa brasileira vêm ocorrendo desde 1985 no município de Pedreira. Com o objetivo de avaliar a prevalência da febre maculosa brasileira nessa área endêmica, foram coletadas amostras únicas de soro de 473 pessoas sadias, moradores e funcionários de uma indústria de louças. As amostras obtidas foram testadas através da reação de imunofluorescência indireta (IFA), para determinação do título de anticorpos para ricketttsia do grupo da febre maculosa brasileira. Vinte e cinco (5,3\%) foram considerados positivos (título $\geq 1: 64)$ e trinta e um (6,5\%) apresentaram título igual a 1:32 ("borderline"). Os resultados evidenciam uma taxa de soropositividade semelhante a outras áreas reconbecidamente endêmicas do país.
\end{abstract}

Palavras-chaves: Febre maculosa. Rickettsias. Inquérito. Diagnóstico laboratorial.

A febre maculosa brasileira, também chamada febre maculosa de São Paulo, tem como agente etiológico a Rickettsia rickettsii, a mesma rickettsia responsável pela febre maculosa das Montanhas Rochosas.

Reconhecida pela primeira vez no Estado de São Paulo em 1929 e, aparentemente, circunscrita a áreas suburbanas da capital, foi identificada em outras regiões do estado e também em Minas Gerais e Rio de Janeiro ${ }^{1361416}$.

Em revisão de literatura realizada por Mancini e cols ${ }^{8}$ sobre a ocorrência de febre maculosa no Brasil, os autores sugerem que a distribuição desta doença pode ser mais ampla do que se supunha, ao reportarem a ocorrência de um caso presuntivo em Salvador, Bahia, em 1979.

No Estado de São Paulo, os dados disponíveis sobre registro sistemático desta doença são escassos. Travassos e Valejo Freire ${ }^{17} \mathrm{em}$ publicação do ano de 1945 relacionam uma vasta área do estado onde teriam ocorrido casos de febre maculosa, sem no entanto discutirem a fonte de seus dados, visto ser outro o objetivo principal do artigo.

Instituto Adolfo Lutz, Campinas, SP. Instituto Adolfo Lutz, São Paulo, SP. Superintendência de Controle de Endemias, Campinas, SP.

Endereço para correspondência: $\mathrm{Dr}^{\mathrm{a}}$ Vania Martins Fontes Del Guercio. IAL de Campinas. R. São Carlos 720, 13035-420 Campinas, SP, Brasil. Fax: (019) 233-7977.

Recebido para publicação em 01/12/95.
Após esse período, encontram-se na literatura registros da ocorrência de 53 casos da doença no período de 1957 a 1974 e de outros 10 casos, de 1976 a 1982, todos eles internados no Hospital Emílio Ribas. A maioria desses indivíduos residia na zona rural de municípios vizinhos a capital de São Paulo, tais como Mogi das Cruzes, Diadema e Santo André ${ }^{1416}$.

Em 1988 foi isolada rickettsia de um caso de febre maculosa proveniente da zona rural de Mogi das Cruzes, SP ${ }^{10}$, com comprovação sorológica e caracterização da amostra isolada por PCR (R Regnery: comunicação pessoal, 1990).

Em 1985 foi feita suspeita diagnóstica de febre maculosa brasileira em três indivíduos residentes no Município de Pedreira, SP, (longitude 46॰54'07"; latitude 22\%44'21") (Figura 1), tendo um deles ido a óbito. Não havia registro da doença, anterior a esta data, nos serviços de saúde do município?.

No ano seguinte, foram levantadas mais quatro suspeitas diagnósticas entre as quais registraram-se três óbitos. Em 1987, de três casos suspeitos da doença, dois tiveram a confirmação do diagnóstico através da reação de imunofluorescência indireta. A incidência anual média foi de 10,9 (desvio padrão 5,12) casos com suspeita clínica por 100.000 habitantes, para o período de 1985 a 1988. O coeficiente de incidência anual médio para o sexo feminino foi de 5,8 (desvio padrão 3,9 ) casos com suspeita clínica por 100.000 mulheres e, para o sexo masculino, de 14,13 (desvio 
Del Guercio VMF, Rocha MMM, Melles HHB, Lima VCL, Pignati MG. Febre maculosa no município de Pedreira, SP, Brasil. Inquérito sorológico. Revista da Sociedade Brasileira de Medicina Tropical 30:47-52, janfev, 1997.

padrão 12,23) casos com suspeita clínica por 100.000 homens. A população anual foi calculada a partir dos valores encontrados nos recenseamentos de 1980 e $1991^{4}$.

Observou-se também um índice médio anual de letalidade elevado, $35,2 \%$ (desvio padrão 30,7 ), se considerarmos o mesmo período e todos os casos com suspeita clínica.

A partir de 1989 até 1992 não foram registrados casos da doença. Em 1993 voltaram a ser diagnosticados 3 casos sendo que um deles era residente em outro município tendo se deslocado para Pedreira para atividade de lazer (pesca); desconsiderando-se este caso, encontra-se uma incidência de 6,8 casos por 100.000 habitantes neste ano. Dois destes pacientes faleceram.

A febre maculosa pode cursar assintomática ou com sintomas frustros ${ }^{2} 111315$. Tendo em mente esta possibilidade e as características de ser doença não corriqueira na área e de não estar no rol de doenças de notificação compulsória, é bem provável que a incidência acima não represente $\mathrm{o}$ risco de adoecer de febre maculosa no município. É interessante observar que apesar do trabalho educativo realizado, junto à população e à comunidade médica local, continua havendo retardo no diagnóstico, o que tem contribuído para a gravidade dos casos ${ }^{18}$. As suspeitas diagnósticas têm sido feitas, em geral, pelos hospitais universitários que são a referência de atenção terciária da região.

Estes são fatores que contribuem também para que se suponha que a incidência da doença seja maior do que a conhecida através dos casos que chegam a ser registrados pelas autoridades de saúde.

Com o objetivo de conhecer o nível de transmissão dessa rickettsiose na área e estimar o risco ao qual está submetida sua população resolveu-se realizar um levantamento sorológico. Em função dos recursos disponíveis, decidiuse estudar apenas a localidade que havia apresentado o maior número de casos no período de 1985 a 1988.

A escassez de estudos sobre a febre maculosa no país, havendo apenas dois levantamentos sorológicos já realizados, ambos em Minas Gerais, também serviu de incentivo para se promover este estudo com a finalidade de contribuir para o conhecimento da epidemiologia local desta doença ${ }^{36}$.

\section{MATERIAL E MÉTODOS}

A localidade rural selecionada para o estudo situa-se às margens da rodovia SP-095 (João Beira), a $2,5 \mathrm{~km}$ da zona urbana do Município de Pedreira.

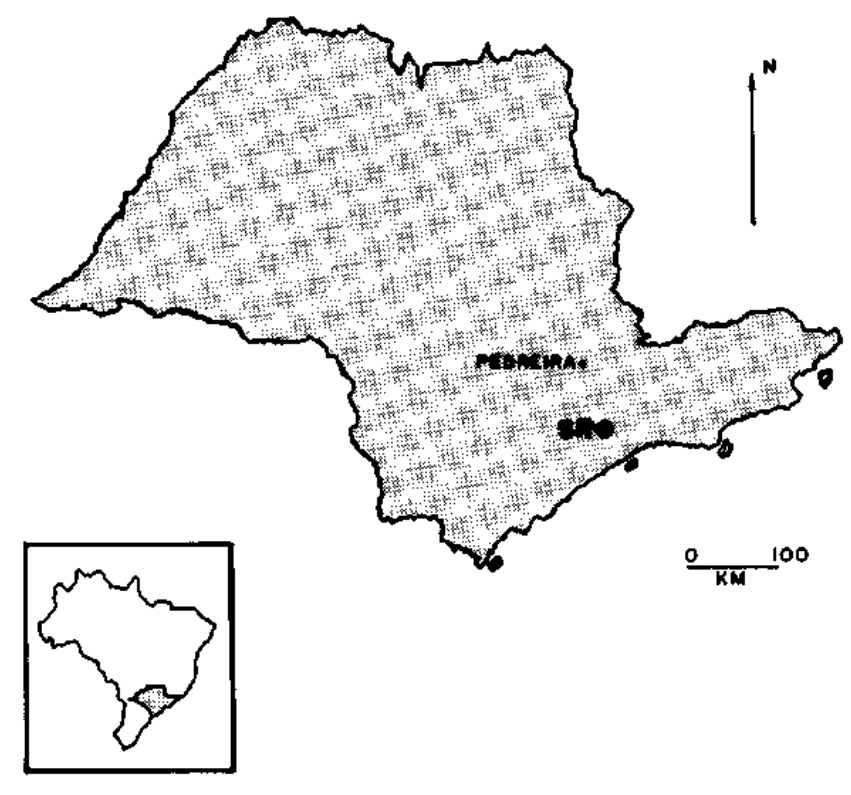

Figura 1 - Mapa do Estado de São Paulo com a localização do município de Pedreira em relação à capital. 
Del Guercio VMF, Rocha MMM, Melles HHB, Lima VCL, Pignati MG. Febre maculosa no município de Pedreira, SP, Brasil. Inquérito sorológico. Revista da Sociedade Brasileira de Medicina Tropical 30:47-52, janfev, 1997.

Nela estão instaladas uma represa hidroelétrica e uma indústria de louças. Existe ainda uma colônia com 200 residências onde uma parte dos trabalhadores reside.

Pretendeu-se estudar toda a população residente na localidade e também os trabalhadores da fábrica que não residiam no local, visto que estes também freqüentavam a área para lazer (pesca, jogo de futebol).

Após entendimentos com a administração da indústria de louças, todas as residências da colônia foram visitadas e, nesta ocasião, os moradores foram informados quanto ao objetivo do trabalho, assinando uma carta de permissão de se submeterem ao exame após terem concordado em participar do projeto.

Foram coletadas 473 amostras únicas de sangue da população em estudo. Isto representou $55 \%$ do total de pessoas existentes. As perdas se deveram à recusa e aos faltosos no dia da coleta.

A coleta do sangue foi realizada no posto médico da localidade. Foi orientado jejum prévio, colhendo-se um volume de 8 a $10 \mathrm{ml}$ de sangue de cada indivíduo, utilizando-se do sistema "vacuntainer". As amostras foram transportadas em caixas de isopor com gelo até ao laboratório, onde se obteve o soro que foi estocado a $-20^{\circ} \mathrm{C}$ até o momento da realização do teste sorológico.

O método utilizado para detecção de anticorpos da classe IgG anti-rickettsias no soro foi a imunofluorescência indireta (IFA) utilizando como substrato antigênico, antígeno do grupo da febre maculosa (Rickettsia rickettsii) e antígeno do grupo tifo (Rickettsia prowazekii). Foram considerados positivos os soros com títulos de anticorpos maiores ou iguais a 1:64, em amostra única de soro, com intensidade de fluorescência maior ou igual
$2+$. Os títulos de anticorpos iguais a 1:32 foram considerados como "borderline".

\section{RESULTADOS}

Vinte e cinco das 473 amostras testadas pelo método IFA apresentaram título maior ou igual a 1:64 para rickettsia do grupo da febre maculosa o que representa $5,3 \%$ de amostras positivas. Trinta e uma $(6,5 \%)$ amostras mostraram resultados considerados "borderline" com titulagem de anticorpos de 1:32.

Observou-se uma nítida predominância do sexo feminino entre os sorologicamente positivos (Tabela 1). Em todas as faixas etárias a prevalência de casos sorologicamente positivos é maior no sexo feminino. Observase ainda nesta tabela que em ambos os sexos ocorrem picos de prevalência nas faixas etárias de 10 a 19 anos e nas de maiores de 49 anos, registrando-se ainda uma prevalência elevada para a faixa de 40 a 49 anos no sexo feminino. As prevalências mais baixas foram encontradas entre as idades de 20 a 39 anos para ambos os sexos.

Os casos que apresentaram resultados "borderline" se comportaram de maneira diferente dos positivos, apresentando uma prevalência semelhante para ambos os sexos e prevalências significativas para as faixas etárias entre 20 e 39 anos (Tabela 2).

\section{DISCUSSÃO}

O significado de uma prevalência sorológica de $5,3 \%$ de amostras com titulagem $\geq 1: 64$ é o de que esta parcela da população em estudo teve infecção rickettsial nos últimos anos $^{15}$. Com esta titulagem nenhum soro de paciente sem rickettsiose seria positivo de acordo com Newhouse ${ }^{12}$. Poderia haver reação

Tabela 1 - Prevalência sorológica de febre maculosa, por faixa etária e sexo-Pedreira, 1991.

\begin{tabular}{|c|c|c|c|c|c|c|c|}
\hline \multirow{2}{*}{$\begin{array}{l}\text { Faixa } \\
\text { etária }\end{array}$} & \multicolumn{3}{|c|}{ Masculino } & \multicolumn{3}{|c|}{ Feminino } & \multirow[b]{2}{*}{ Total } \\
\hline & examinados & posit & $\%$ & examinados & posit & $\%$ & \\
\hline Ignorado & 6 & & 0 & 7 & 1 & 14,3 & 13 \\
\hline 1 a 4 & 6 & - & 0 & 3 & - & & 09 \\
\hline 5 a 9 & 4 & - & 0 & 14 & - & & 18 \\
\hline 10 a 19 & 60 & 4 & 6,7 & 51 & 5 & 9,7 & 111 \\
\hline 20 a 29 & 69 & 2 & 2,9 & 66 & 4 & 6,0 & 135 \\
\hline 30 a 39 & 35 & - & 0 & 46 & 2 & 4,2 & 81 \\
\hline 40 a 49 & 39 & 1 & 2,6 & 27 & 3 & 11,0 & 66 \\
\hline$>49$ & 28 & 2 & 7,1 & 12 & 1 & 8,2 & 30 \\
\hline Total & 247 & 9 & 3,5 & 226 & 16 & 7,1 & 473 \\
\hline
\end{tabular}


Del Guercio VMF, Rocha MMM, Melles HHB, Lima VCL, Pignati MG. Febre maculosa no município de Pedreira, SP, Brasil. Inquérito sorológico. Revista da Sociedade Brasileira de Medicina Tropical 30:47-52, janfev, 1997.

\begin{tabular}{|c|c|c|c|c|c|c|c|}
\hline \multirow{2}{*}{$\begin{array}{l}\text { Faixa } \\
\text { Etária }\end{array}$} & \multicolumn{3}{|c|}{ Masculino } & \multicolumn{3}{|c|}{ Feminino } & \multirow[b]{2}{*}{ total } \\
\hline & examinados & borderline & $\%$ & examinados & bordelaine & $\%$ & \\
\hline$<1$ & 6 & - & 0 & 7 & - & 0 & 13 \\
\hline 1 a 4 & 6 & - & 0 & 3 & - & 0 & 09 \\
\hline 5 a 9 & 4 & - & 0 & 14 & 1 & 7,0 & 18 \\
\hline 10 a 19 & 60 & 7 & 11,71 & 51 & 2 & 3,8 & 111 \\
\hline 20 a 29 & 69 & 2 & 2,91 & 66 & 5 & 7,6 & 135 \\
\hline 30 a 39 & 35 & 3 & 8,6 & 46 & 3 & 6,4 & 81 \\
\hline 40 a 49 & 39 & 3 & 7,7 & 27 & 3 & 11,0 & 66 \\
\hline$>49$ & 28 & 2 & 7,0 & 12 & - & 0 & 30 \\
\hline Total & 247 & 17 & 6,9 & 226 & 14 & 6,2 & 473 \\
\hline
\end{tabular}

cruzada com as espécies de rickettsias do mesmo sorogrupo, contudo, até o momento, no Brasil, do grupo da febre maculosa, só houve isolamento da Rickettsia rickettsii. ${ }^{6}$

No Brasil, este é o terceiro estudo sobre prevalência da febre maculosa, e evidencia que 5,3\% da população observada em Pedreira tiveram estimulação imune-prévia a antígenos do grupo da febre maculosa.

O título mínimo positivo para confirmar infecção por rickettsia, através da reação de imunofluorescência, é designado considerando que pessoas sadias, ocasionalmente, reagem em baixos títulos.

Levando em conta estas considerações e alguns trabalhos realizados ${ }^{512}$, e de acordo com critérios estabelecidos pelo CDC foram considerados positivos os soros com títulos de anticorpos fluorescentes 1:64, e títulos 1:32 como "borderline" em uma única amostra de soro, assegurando a especificidade do teste.

Se considerarmos os 25 pacientes com a titulagem de 1:64 e calcularmos o coeficiente de prevalência considerando a população total do município para o ano de 1991, encontraremos um valor de 89,3 casos sorologicamente positivos por 100.000 habitantes. Mesmo que a prevalência sorológica signifique um acúmulo de casos dos últimos anos e não só daqueles que adquiriram a infecção naquele ano, a diferença é muito grande entre os valores da incidência de casos suspeitos e o da prevalência de infecção, o que demonstra a existência de um considerável número de casos não diagnosticados, provavelmente subclínicos ou assintomáticos. A verdadeira prevalência de infectados não pode ser avaliada pelos testes sorológicos disponíveis, pois em casos de doença comprovada, os anticorpos detectáveis por Inibição de Hemaglutinação e por Imunofluorescência Indireta podem, também, cair a níveis baixos ou não detectáveis nos anos seguintes à doença ${ }^{19}$.
Considerando a diluição $\geq 1: 64$, a prevalência encontrada no presente estudo se situa acima daquela observada por Galvão ${ }^{3}$, na localidade de Córrego dos Marceneiros (2,1\%) e mais baixa do que a encontrada por Lemos ${ }^{6}$, no município de Santa Cruz do Escalvado $(7,1 \%)$, ambos no Estado de Minas Gerais. Neste último estudo a autora também calculou as prevalências de infecção por localidades estudadas. Os resultados das oito localidades variaram de zero a $11,1 \%$. Estes resultados podem ter sido influenciados pela ocorrência de uma epidemia nos anos imediatamente anteriores ao levantamento sorológico. Galvão, no seu estudo, levanta a possibilidade de explicação da baixa prevalência encontrada, nestes níveis de diluição, devido ao intervalo considerado de 2 anos e 41 dias, entre a ocorrência de casos suspeitos da doença e seu levantamento.

Foram registrados os resultados das amostras reagentes a 1:32 porque, sendo a perspectiva deste estudo avaliar o nível da transmissão e o risco de adquirir a infecção na localidade, se não considerássemos os pacientes com reação a este nível de diluição, estaríamos perdendo uma quantidade significativa de pessoas infectadas por Rickettsia do grupo da febre maculosa. O teste de IFA, reagente a esta diluição, pode apresentar 0,2\% de falsos positivos, mas a sua sensibilidade é de 97,4\%, sendo maior que a sensibilidade no nível de diluição de 1:64 que é de $84,6 \%{ }^{12}$. A prevalência de positividade encontrada na diluição de 1:32, (excluindo-se os que reagiram a diluições mais elevadas, discutidos acima), foi bem mais baixa do que a encontrada por Galvão (31,75\%). Estes achados podem sugerir, no caso de Pedreira, que estavamos com transmissão ativa por ocasião do levantamento e, no estudo do Galvão, estar-se-ia diante de um declínio na quantidade de anticorpos no 
Del Guercio VMF, Rocha MMM, Melles HHB, Lima VCL, Pignati MG. Febre maculosa no município de Pedreira, SP, Brasil. Inquérito sorológico. Revista da Sociedade Brasileira de Medicina Tropical 30:47-52, janfev, 1997.

sangue dos indivíduos examinados. Podemos concluir com estes conhecimentos que o município, ora estudado, apresenta níveis de transmissão da febre maculosa semelhante às areas reconhecidamente endêmicas do país.

No que diz respeito à prevalência por sexo e faixa etária, seriam necessárias mais informações para que se pudesse aventar hipóteses explicativas. Como se sabe, o comportamento do Amblyomma cajennense é eclético variando muito também as especificidades dos tipos de ocupação do espaço geográfico pelas populações humanas. Em decorrência disso, pode-se encontrar diversos perfis epidemiológicos que vão estar relacionados à diversas condições geográficas, à diversas condições de organização socioeconomicas, etc. Por razões alheias a nossa vontade, não foi possível realizar inquérito com a população a respeito de tempo de moradia no local, hábitos, ocupação, condições de vida e lazer, sintomas anteriores, etc. Desta maneira, não encontramos explicações para a predominância do sexo feminino entre os sorologicamente positivos, principalmente, se fizermos uma comparação com a prevalência de casos suspeitos notificados por sexo e com a prevalência por sexo entre os casos, considerados "borderline", no presente estudo.

Vale a pena citar que no trabalho de Lemos foi encontrada grande variação, entre as diversas localidades estudadas, no que diz respeito à faixa etária e sexo mais antingidos pela infecção. Em uma das localidades houve uma predominância nítida do sexo feminino. Galvão encontrou uma discreta predominância do sexo masculino na localidade trabalhada, diferença considerada por ele como não significativa.

No presente estudo, temos ainda que levar em consideração ao analisar a distribuição por sexo e faixa etária que como só foram coletadas amostras de $55 \%$ da população e não se conhecem as características de quem não se submeteu ao exame, estas variações encontradas podem não estar retratando a realidade.

Ressaltamos no entanto que nos Estados Unidos, também foram encontrados diferentes comportamentos da prevalência da Febre das Montanhas Rochosas, no que diz respeito ao sexo, tendo sido relacionada esta diferença com a espécie de carrapato envolvida com a transmissão ${ }^{6}$.

Podemos concluir, por fim, que a prevalência de infecção por rickettsia do grupo da febre maculosa encontrada através de análise sorológica, na localidade estudada no município de Pedreira, sugere ser esta área endêmica para a febre maculosa e a coloca num nível de endemicidade semelhante a outras áreas reconhecidamente endêmicas do país.

São necessários mais estudos para um conhecimento mais aprofundado dos determinantes da epidemiologia da enfermidade no município.

\section{SUMMARY}

Cases of Brasilian spotted fever (BSF) have been occurred since 1985, in the rural area of Pedreira town, situated $160 \mathrm{~km}$ away from the city of São

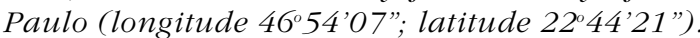
Aiming at evaluating the prevalence of Brasilian spotted fever in this endemic area, single-serum samples were collected from 473 healthy persons, amongst city-dwellers and the local china industry workers. The obtained samples were tested by indirect immunofluorescence (IFA), in order to determine the antibodies titer for the group of Brasilian spotted fever. Twenty-five (5.3\%) were considered positive (titer 3 1:64) and thirty-one (6.5\%) were taken as "borderline" (titer 1:32). The results show a serologically positivity rate similar to other areas, known as endemic ones within the country.

Key-words: Spotted fever. Rickettsia. Survey. Laboratory diagnosis.

\section{REFERÊNCIAS BIBLIOGRÁFICAS}

1. Dias E, Martins AV. Spotted Fever in Brasil. A summary. The American Journal of Tropical Medicine and Hygiene 19:103-108, 1939.

2. Fishbein DB, Kaplan JE, Bernard KW, Winkler WG. Surveillance of Rock Montain spotted fever in the United States, 1981-1983.The Journal of infectious Diseases 150:609-611, 1984.

3. Galvão MAM.A febre Maculosa Brasileira em Minas Gerais e seus determinantes. Tese de Mestrado - Escola Nacional de Saúde Pública, Rio de Janeiro, RJ, 1988.

4. Instituto Brasileiro de Geografia e Estatística, Censo Demográfico, 1991.

5. Kaplan JE, Schoenberger LB. The sensitivity of various serological tests in the diagnosis of Rocky Mountain spotted fever. The American Journal of Tropical Medicine and Hygiene 35:840-844, 1986.

6. Lemos ERS. Aspectos epidemiológicos da riquetsiose do grupo da febre maculosa em uma 
Del Guercio VMF, Rocha MMM, Melles HHB, Lima VCL, Pignati MG. Febre maculosa no município de Pedreira, SP, Brasil. Inquérito sorológico. Revista da Sociedade Brasileira de Medicina Tropical 30:47-52, janfev, 1997.

área endêmica do Estado de Minas Gerais. Tese de Mestrado, Instituto Oswaldo Cruz, Rio de Janeiro, RJ, 1991.

7. Lima VCL, Figueiredo AC, Pignatti MG, Modolo M. Febre maculosa no município de Pedreira, Estado de São Paulo - Brasil - Relação entre ocorrência de casos e parasitismo humano por ixodideos. Revista da Sociedade Brasileira de Medicina Tropical 28:135- 137, 1995.

8. Mancini DAP, Nascimento EMM, Tavares VR, Soares MA.A ocorrência de riquetsioses do grupo Rickettsia rickettsii. Revista de Saúde Pública 17:493-499, 1983.

9. Marx RS, McCall CE, Abramson JS, Harlan JE. Rocky Mountain spotted fever: serological evidence of previous subclinical infection in children. The American Journal of Diseases of Children 136:16-18, 1982.

10. Melles HHB, Colombo S, Silva MV. Febre maculosa: Isolamento de Rickettsia em amostra de biópsia e pele. Revista do Instituto de Medicina Tropical de São Paulo 34:37-41, 1992.

11. Ming-Yuan F, Walker DH, Qing-Huai L, Han L, HaiChun B, Jia-Ke Z, Lenz B, Hong C. Rickettsial and serologic evidence for prevalent spotted fever rickettisiosis in inner Mongólia. The American Journal of Tropical Medicine and Hygiene 36:615620, 1987.

12. Newhouse VF, Shepard CC, Redus MD, Tzianabos T, McDade JE. A comparison of the complement fixation, indirect fluorescent antibody and microagglutionation tests for the serological diagnosis of rickettsial diseases. The American Journal of Tropical Medicine and Hygiene 28:387$395,1979$.
13. Philip RN, Casper EA, Ormsbee RA, Peacock MG, Burgdorfer W. Microimmunofluorescence test for the serological study of Rock Mountain spotted fever and typhus. Journal of Clinical Microbiology 3:51-61, 1976.

14. Rosenthal C. Riquetsioses. In: Amato Neto (ed) Doenças Transmissíveis. Savier, São Paulo. p. 737751, 1989.

15. Taylor PJ, Tanner WB, Rawlings JA, Buck J, Elliot LB, Dewlett HJ, Taylor B, Betz TG. Serological evidence of subclinical Rock Mountain spotted fever infections in Texas. The Journal of infectious diseases 151:367-369, 1985.

16. Tiriba AC. Geografia Médica das Riquetsioses. In: Lacaz CS, Baruzzi RG, Siqueira Jr WS (eds) Introdução à Geografia Médica do Brasil. Ed. Edgard Blucher Ltda, São Paulo, 1972.

17. Travassos J, Vallejo-Freire A. Criação artificial de Amblyomma cajennense para o preparo de vacina contra a febre maculosa. Memórias do Instituto Butantã 18:145-235, 1944-1945.

18. Wilfert CM, MacCormack JN, Kleeman K, Philip RN, Austin E, Dickinson V,Turner L. Epidemiology of Rocky Mountain spotted fever as determined by active surveillance. The Journal of Infectious diseases 150:469-479, 1984.

19. Wilfert CM, MacCormack JN, Kleeman K, Philip RN, Austin E, Dickinson V, Turner L. The prevalence of antibodies to Rickettsia rickettsii in an area endemic for Rocky Mountain spotted fever.The Journal of Infectious Diseases 151:823$831,1985$. 